\title{
¿Podemos seguir hablando de "la mujer" como sujeto del discurso feminista?: Reflexiones a la luz de los discursos de padres separados ${ }^{* *}$
}

\author{
Can we keep talking about "women" as a subject of \\ feminist discourse?: Reflections from the perspective of \\ divorced parents
}

Podemos continuar falando sobre "mulheres" como sujeito do discurso feminista?: Reflexões à luz dos discursos de pais separados

\footnotetext{
* Psicóloga de la Universidad Externado de Colombia, Candidata a Doctora en Estudios Interdisciplinares de Género de la Universidad de Salamanca. Docente e investigadora en la Universidad Cooperativa de Colombia, institución que le ha dado reconocimientos por su labor investigativa y su visibilidad internacional. Sus áreas de interés son las masculinidades, la violencia de género y la psicolingüística en relación a la variable género. En el año 2014 recibió la Beca Jóvenes Profesores Investigadores del Banco Santander para realizar investigación en la Universidad de Salamanca en España. Correo electrónico: anni.garzons@campusucc.edu.co

** Este artículo es producto de la investigación titulada: "No todos los hombres ni los padres son iguales: Acerca de las prácticas y discursos de identidad y rol de género en padres separados". Artículo recibido el 31/01/2015 y aprobado el 09/04/2015.
} 


\section{Resumen}

Abstract

Resumo

Este artículo reflexiona alrededor del sujeto del discurso feminista, a la luz de los discursos de hombres colombianos, que son padres y separados. Los cambios en los roles e identidades de género de hombres y mujeres, así como de sus propias percepciones sobre la política y la igualdad. Estos discursos se obtuvieron a través de una investigación mixta con 88 padres separados, de los cuales diez fueron entrevistados sobre sus percepciones de la experiencia de separación conyugal. Se parte de la construcción histórica del feminismo y se finaliza con la discusión en torno a las tensiones y encuentros del mismo con los colectivos de hombres y nuevas masculinidades.

\section{PALABRAS CLAVE:}

Feminismo | hombres | mujeres | masculinidades | género

This paper presents reflects upon the subject of feminist discourse based on the discourses of colombian male separated parents about changes in men and women and their perceptions of politics and equality. These discourses were obtained throughout a mixed research with 88 separated parents, ten of whom were interviewed in search of their perceptions from his experience of marital separation. The paper begins with the historical construction of feminism and ends with the discussion on the tensions and agreements with the groups of men and new masculinities.

\section{KEYWORDS:}

Feminism | men | women | masculinities | gender

Este artigo reflete em torno do sujeito do discurso feminista, à luz dos discursos dos homens colombianos que são pais e separados sobre as mudanças nos papéis e identidades de gênero dos homens e mulheres, bem como suas próprias percepções da política e igualdade. Esses discursos foram obtidos através de uma pesquisa conjunta com 88 pais separados, dos quais dez foram entrevistados sobre suas percepções da experiência de separação conjugal. 
Inicia-se a partir da construção histórica do feminismo e termina-se com a discussão sobre as tensões e encontros com grupos de homens e novas masculinidades.

\section{PALAVRAS-CHAVE:}

Feminismo | homens | mulheres | masculinidade | sexo 


\section{Introducción}

¿Podemos seguir hablando de "la mujer" como sujeto del discurso feminista? ¿Cuáles serían las ventajas y desventajas de este concepto para la misma práctica feminista? La pregunta acerca del sujeto del discurso feminista es clave en los espacios públicos y académicos, ya que encamina las exigencias, vindicaciones e intereses políticos de los movimientos feministas, así también las investigaciones y reflexiones de las personas dedicadas a su estudio. Estas son preguntas que permiten evaluar o incluso reestructurar la agenda del feminismo actual. Para responderlas es clave remontarse de forma breve al proceso histórico del feminismo, sus principales preocupaciones y las consecuencias que éstas han tenido y las que pueden tener.

En la historia del feminismo (Beltrán, Maqueira, Álvarezy Sánchez, 2001) la primera ola es la del feminismo ilustrado del siglo XIX: el derecho al voto de la mujer, junto a otros derechos reclamados, expusieron la demanda de individualidad, el reconocimiento de las mujeres como sujetos autónomos y racionales que pueden apropiarse de su destino.

La segunda ola corresponde al feminismo del siglo XX (años 60 y 70 ): los feminismos liberal, radical y socialista, que revelan la preocupación de este periodo por la identidad de las mujeres, por la diferencia y la sexualidad. Estos feminismos resultan muy importantes para comprender el desarrollo actual de la teoría feminista. Es de destacar la importancia de sus vindicaciones, pues trascienden la lucha sufragista al sacar a la luz cuestiones que afectaban a las mujeres en su vida cotidiana, tales como el derecho a la educación, la inclusión en el mercado laboral o la autonomía y libertad para decidir sobre su sexualidad.

Retomando de forma breve a Friedan (1964), una de las representantes del feminismo liberal, éste puede entenderse como la reivindicación de la igualdad con una fuerte carga legalista. Según dos representantes del feminismo radical, Millet (1970) y Firestone (1970), éste denuncia la opresión y la subordinación en que se encuentran las mujeres, y realiza las primeras explicaciones del patriarcado como sistema de dominación de los hombres sobre las mujeres a través del autoritarismo, la explotación y la represión sexual. El feminismo socialista se propone aplicar la teoría marxista de la explotación al análisis sobre la situación de las mujeres, considerando al trabajo doméstico y la unión del patriarcado con el capitalismo como la causa de la subordinación de las mujeres.

En recientes décadas (años 80, 90 y primera década del siglo XXI), se consolida la categoría de género como herramienta de análisis de los procesos de desigualdad entre hombres y mujeres. Tomando esto en cuenta, se puede entender al género como la construcción sociocultural de lo masculino y lo femenino y sus consecuencias en la organización social (Godoy, 2010). El género pone en juego los conceptos de diferencia y de desigualdad, y se retoman críticamente las principales dicotomías presentes en la historia del pensamiento occidental, las cuales han actuado como justificación de tal 
desigualdad, tales como: naturaleza-cultura, individuo-sociedad, doméstico-público, hogar-trabajo.

Una vez terminado este breve recuento en torno a algunos de los principales intereses del feminismo a lo largo de su historia, resultan importantes algunas aclaraciones para responder la pregunta sobre el sujeto del feminismo, que guíen la discusión y su posible respuesta. Por un lado, es importante reconocer la pluralidad del feminismo, y por tanto hablar de "feminismos"; por otro lado, tener en cuenta que esta pluralidad de enfoques feministas no pierde de vista dos temas y objetivos comunes, a saber: la igualdad y la emancipación de la mujer, que siguen siendo centrales a los discursos feministas. Las mujeres parecen situarse en el centro del discurso feminista; sin embargo, un análisis más detallado permite reconocer una mayor complejidad en este asunto: la igualdad remite a un asunto social relacional que no se limita a hablar exclusivamente de la mujer, es también hablar de los varones y, por tanto, de sus relaciones enmarcadas en el sistema patriarcal.

Esta distinción entre varones y mujeres nos remite una vez más al concepto de género como categoría de análisis social, incluida dentro de los feminismos. Considerando esto, surgen otras preguntas: ¿es entonces el género el tema central de los feminismos?, ¿es equiparable el género al feminismo?, ¿hablar de género es hablar de las mujeres? Frente a esto, Lagarde plantea:

Ya es aceptado que cuando se usa el concepto perspectiva de género se hace referencia a la concepción académica, ilustrada y científica, que sintetiza la teoría y la filosofía liberadora, creadas por las mujeres y forma parte de la cultura feminista. La perspectiva de género permite analizar y comprender las características que definen a las mujeres y a los hombres de manera específica, así como sus semejanzas y diferencias... Las múltiples distorsiones de la perspectiva de género provienen también de su uso exclusivo para analizar a las mujeres y desarrollar programas con ellas, aun cuando la teoría de género permite analizar, comprender y develar a los hombres. El contenido relacional de la teoría de género es omitido, así como su definición histórica y los contenidos de género de la sociedad, el Estado y la cultura. Limitar la perspectiva de género a las mujeres exige una complicada transacción encubierta: si no se parte del contenido analítico filosófico feminista y si por género se entiende mujer, se neutralizan el análisis y la comprensión de los procesos, así como la crítica, la denuncia y las propuestas feministas (Lagarde, 1996: 24).

Desde esta autora, la perspectiva de género es base analítica y metodológica del feminismo en su lucha por la igualdad, y permite reconocer que en esa búsqueda el género implica a hombres y mujeres como seres humanos incorporados a un sistema patriarcal de dominación (Alonso, 2005).

Entonces, si los feminismos tienen una perspectiva de género, ¿los conceptos de género y de feminismo son equiparables? Valcárcel (2008) plantea que el feminismo 
considera que ningún individuo de la especie humana debe ser privado de cualquier bien o derecho a causa de su género, y que aunque la categoría de género es fundamental para el análisis social, no debe sustituir al feminismo, pues tal sustitución respondería a una estrategia patriarcal que convierte al feminismo en un innombrable, debido a sus planteamientos en contra del sistema. Además plantea que reemplazarla representa ignorar la lucha e historia del feminismo. Concluye así que el feminismo no debe ser sustituido ni por el género ni por los mujerismos, ${ }^{1}$ entendiendo que no siempre hablar de mujer es hablar desde el feminismo, pues el feminismo tiene una lucha particular en favor de la igualdad y el reconocimiento de la mujer como ser humano.

Teniendo en cuenta lo anterior, a continuación se expondrá el método usado en la investigación titulada "No todos los hombres ni los padres son iguales: Acerca de las prácticas y discursos de identidad y rol de género en padres separados", de la cual se tomaron los discursos que se presentarán más adelante para reflexionar en torno a las preguntas planteadas antes.

\section{Método}

"No todos los hombres ni los padres son iguales: Acerca de las prácticas y discursos de identidad y rol de género en padres separados", fue una investigación mixta de tipo exploratorio descriptivo con 89 hombres colombianos en situación de separación conyugal que tuvieran hijos. 50 de ellos formaban parte de la Fundación Padres por Siempre: "La fundación es un colectivo de padres (papás y mamás) que luchamos por la defensa completa de los derechos de los niños, por la implantación de la custodia compartida, contra todo tipo de discriminación, por los derechos humanos y la construcción de la nueva masculinidad" (Fundación Padres por Siempre, 2015) y 39 de los padres se contactaron a través del Colegio Gerardo Paredes Martínez. Los participantes se encontraban en su mayoría en el rango de los 38 a 44 años (39\%), principalmente residentes de la ciudad de Bogotá (69\%); en su mayoría (34\%) en el estrato socioeconómico 3 (medio-bajo), seguidos de los estratos $2(29 \%)$ y 4 (20\%); en su mayoría son profesionales $(53 \%)$.

Se aplicó una encuesta sobre sus actividades antes y después de la separación, así como sobre sus definiciones de mujer, hombre, paternidad, maternidad, masculinidad, feminidad, y sobre roles e identidades de género. De los 89 hombres se seleccionaron 10 sujetos (de diferentes estratos socioeconómicos, profesiones, nivel educativo, edades de

\footnotetext{
1. Amelia Miyares en 1999 aclaró el concepto de "Mujerismo", definiéndolo como la apelación al papel de madres y esposas, y las capacidades que esto conlleva; lo entiende como vulgarización del esencialismo de las mujeres pues es usado por los partidos políticos de izquierda o derecha para mostrar que se están incluyendo las mujeres; sin embargo, las militantes de estos partidos mantienen discursos patriarcales que difunden la visión tradicional y dicotómica de los roles de las mujeres y de los hombres.
} 
los hijos y con motivos de separación diferentes) que pudieran enriquecer las perspectivas buscadas por la indagación, mediante una entrevista a profundidad.

Para el procesamiento de los datos se utilizó una técnica de análisis cuantitativo, la estadística descriptiva (programa Microsoft Excel); para el análisis cualitativo, la teoría fundamentada a través del programa Atlas ti. Este artículo hace énfasis en el análisis de orden cualitativo producto de la investigación previamente mencionada, con el objetivo de reflexionar a la luz de los discursos de los participantes que aportan a la indagación sobre el sujeto en el feminismo.

\section{Resultados}

Las experiencias de paternidad en hombres separados resultan muy interesantes debido a que la separación conyugal es una experiencia que genera tanto cambios como permanencias, en relación a las prácticas y discursos de género, específicamente en: la paternidad, la división sexual del trabajo doméstico y las definiciones sobre el deber ser del hombre o la mujer, así como su identidad de género en relación a estas definiciones. En seguida se presentarán los resultados divididos en dos ejes claves: 1) Cambios percibidos en las mujeres y los hombres, es decir, cambios visibilizados por los participantes en los roles e identidades de hombres y mujeres con respecto a generaciones anteriores, y como resultado de la revolución feminista; y 2) Perspectivas en torno a política e igualdad; importancia y significados atribuidos al ordenamiento jurídico, los movimientos sociales y las políticas públicas para la consecución de la igualdad de derechos y oportunidades entre hombres y mujeres.

\section{Cambios percibidos en las Mujeres y los Hombres}

Entre los participantes se evidencia una percepción generalizada que revela el cambio de roles e identidades de género frente a los modelos tradicionales de ser hombre y mujer. Hay dos diferentes posiciones con respecto a estos cambios: por un lado, los que están de acuerdo con los cambios en los roles e identidades de género, y así conformes con la participación de las mujeres en el mercado laboral y educativo, y de los hombres en el ámbito doméstico; por otro lado, están algunos participantes inconformes o en desacuerdo con estos cambios. Los discursos de unos y otros se exponen a continuación. 


\begin{abstract}
"Sí, claro, los hombres se han feminizado y eso es bueno; y las mujeres se han masculinizado y eso es bueno, o sea, las mujeres han asumido más trabajo, los hombres han asumido más hogar, se comprenden mutuamente, entienden el papel del otro mucho más, realmente esa tendencia es histórica, a la larga vamos a ser casi iguales” (Entrevistado 1).

"Ya los roles del hombre y la mujer han cambiado muchísimo, dentro de la pareja, la familia y la sociedad. La mujer tiene otras expectativas de vida, valora otras oportunidades de trabajo, de estudio, y no simplemente se centra en los hijos que puedan tener del matrimonio. El hombre, a su vez, como la mujer, ha encontrado valoraciones adicionales: una tendencia a estar más en casa, ayudar con las labores, cambiar pañales, ser más afectivo con los niños. Ya el hombre deja de ser proveedor, solamente, sino que es tanto proveedor como responsable y generador de afecto hacia sus hijos, o sea, ya se habla de una nueva masculinidad, en la sociedad, es el nuevo hombre y la nueva mujer" (Entrevistado 3).
\end{abstract}

\title{
También se evidencian discursos de los participantes en desacuerdo:
}

“A mí me parecen muy bonitos los principios cristianos, podrán decir que son machistas, pero a mí me parecen que las cosas tienen un derecho. Las mujeres de hoy en día se han anti-naturalizado, son ellas las que le mandan carticas a los hombres y las que les dicen que quieren que sean novios" (Entrevistado 2).

Por otro lado, además de perspectivas sobre los cambios, están las experiencias personales de cambios y permanencias en roles de género, experiencias donde la mujer trabaja pero el hombre sigue siendo el responsable del bienestar económico:

"No, ella decía que a ella le enseñaron que de eso se encargaba el hombre, entonces ella ganaba esa plata para ella. [...] Por eso también tuvimos mucho problema, porque no aportaba económicamente ni se encargaba de cuidar a las niñas, eso siempre lo hizo mi mamá, entonces yo decía: ni aporta económicamente ni cuida las niñas ni nada” (Entrevistado 2).

Experiencias en las que según lo expuesto por uno de los participantes, la mujer madre asume un rol de autoridad, tradicionalmente asumido por el padre:

"La mamá en cierta forma es la que más tiene en casa rigidez y disciplina, porque está más con ellos, le toca asumir ese rol; pero estoy muy contento y creo que la mujer también tiene esa posibilidad, pues le abre otros caminos...” (Entrevistado 3 ).

Experiencias donde hombres tienen trabajos en campos tradicionalmente asociados a la mujer: 
"En el sitio donde yo laboro tengo que estar todos los días, porque yo manejo reinas de belleza, modelos, amas de casa, haciéndoles masajes, máscaras faciales, ese tipo de cosas de la estética, y adicionalmente me dedico a manejar mi fundación” (Entrevistado 4).

Y experiencias donde ellos realizan labores del hogar, tradicionalmente propias de las mujeres:

"Por ejemplo, yo acabo de preparar mi comida, hice todas mis cosas, lavo mi ropa, hago todo" (Entrevistado 4).

Pueden identificarse variadas posiciones sobre los cambios y permanencias de los roles e identidades de género; a continuación se recogen definiciones de los participantes con respecto a cómo es un hombre y una mujer en la actualidad.

El primer aspecto a tener en cuenta es la consideración de un cambio en la forma de ser hombre, al compararse con las generaciones anteriores, este cambio involucra un acercamiento a las labores domésticas y a la afectividad, como exponía uno de los testimonios ya citados: "ya se habla de una nueva masculinidad en la sociedad" (Entrevistado 3 ).

De igual forma, al preguntar a los participantes por el contraste entre el hombre de hoy y el de ayer, ellos hacen referencia al machismo asociado con una relación jerárquica hombre-mujer, en donde el hombre posee el dominio y el poder sobre las decisiones y actuaciones, en especial en el hogar, y la mujer posee un papel pasivo basado en el servicio al hombre y a sus hijos; esta referencia es dada por algunos participantes con una connotación negativa y diferenciadora frente al papel del hombre de hoy:

"Pues yo venía de un hogar machista donde el hombre toma las decisiones, muy machista, él llegaba y que la mujer lo atienda, lo arregla, le tiene la comida, entonces, la sociedad va cambiando" (Entrevistado 3).

Sin embargo, algunos padres participantes consideran que el machismo permanece o que es la forma más adecuada de relación hombre-mujer:

“-¿Y en qué crees que los hombres han cambiado? -Pues no ha sido mucho, creo que siguen siendo machistas. No es por nada, pero aún a las mujeres les cuesta mucho trabajo conseguir un buen empleo y no tienen las mismas oportunidades” (Entrevistado 2).

"A mí me parecen muy bonitos los principios cristianos, podrán decir que son machistas, pero a mí me parecen que las cosas tienen un derecho” (Entrevistado 2).

De tal forma, como se puede notar en estos últimos fragmentos, se da que en la misma persona hay un debate entre ser machista, apoyar el machismo o no serlo y hacerlo; esto 
podría deberse a que el modelo de familia y de roles del hogar de origen se contrasta con los nuevos roles, generando en los participantes una dualidad sobre qué modelo seguir. Ahora bien, en relación con las mujeres, la entrada de las mismas al mercado laboral, su participación política y el acceso a la educación, deben considerarse como una circunstancia fundamental que ha redefinido las relaciones sociales y familiares. De tal forma, la mujer se ha ido posicionando en nuevos ámbitos, más allá de sus tradicionales funciones en el hogar, que han producido a su vez un nuevo posicionamiento de los hombres. A partir de esto, a continuación se presentan percepciones de los padres separados participantes sobre las mujeres, los cambios que ellas han tenido, y las implicaciones de éstos en la vida propia.

Se evidenciaron tres aspectos: primero, el cambio entre las mujeres de generaciones pasadas y las mujeres de generaciones actuales; segundo, muy relacionado con el primero, sobre la percepción de la mujer de pérdida al estar casada; y en tercer lugar, las respuestas dadas por los padres separados a la pregunta sobre cómo debe ser una mujer.

Para empezar, está la perspectiva de que las mujeres de hoy tienen otras expectativas de vida que las distancian de la mujer de antes, centrada exclusivamente en su rol en el hogar. Estas expectativas están relacionadas principalmente con el trabajo:

"La mujer tiene otras expectativas de vida, valora otras oportunidades de trabajo, de estudio, y no simplemente se centra en los hijos que puedan tener del matrimonio" (Entrevistado 3 ).

Los padres separados participantes encuentran que cambió la idea de que ser mujer implicaba por obligación ser madre, por la idea de la maternidad como una posibilidad y elección de las mujeres. Los participantes plantean que hay mujeres que deciden desempeñar su rol de madre y a la vez trabajar en el mercado laboral; y que a la vez hay mujeres que no desean ser madres y deciden no tener hijos.

Acompañado de esto hay diferentes percepciones en algunos participantes sobre la entrada de la mujer al trabajo, por un lado como algo positivo, de lo cual sentirse orgulloso, o por otro lado, las consecuencias que esto trae en la relación con los hombres:

"Uno se siente orgulloso cuando ve que su mujer no es sólo ama de casa, sino que hace de todo. (...) Muchas mujeres usan sus conocimientos y títulos para pisar a los hombres" (Entrevistado 5).

"En la sociedad, con la entrada de la mujer al trabajo, pues digamos, ya ellas son las que mandan, ellas dan problemas, es muchísimo el cambio. Uno se da cuenta que por todo lado ahora la mujer ya es libre, que ya no quiere que nadie la mande, que nadie le diga, que porque ella trabaja, que tiene su plata, que ya no depende de nadie, y pues entonces ahí es donde vienen y ahí comienzan los problemas" (Entrevistado 7). 
Los cambios en las relaciones familiares generan motivos para la separación: el rompimiento con las relaciones patriarcales tradicionales o las consecuencias en relación con los hijos, pues la mujer es pensada como un ser clave en el cuidado de ellos:

"Las mujeres han ganado un gran espacio en la sociedad, lo que ha generado que la gran mayoría de estas sientan gran independencia de los hombres, lo cual ha evitado que sean tan sumisas como en épocas pasadas y por ende esto ha causado que muchos hogares hoy estén destruidos. Sin con esto decir que es culpa de la mujer, lo que pasa es que ahora hay que ser mucho más tolerantes y tener mucho más respeto por la persona con la que compartimos" (Entrevistado 6).

"Una mujer entra en la casa, entra al trabajo y de ahí dependen mucho las separaciones; porque hay mujeres que están enseñadas a eso que llaman liberación, ellas son ellas, ellas son las que quieren: que yo no puedo llegar tarde, que no quiero llegar a la casa temprano, es mi vida, no tiene por qué estarme espiando ni nada. Entonces ahí se juntan con las demás y de ahí vienen los problemas, ya porque llegó tarde, ya porque no llega temprano, qué paso... Ya es mucho el cambio” (Entrevistado 7).

"Pienso que ha sido buena y lo merecen, ya que tienen los mismos derechos que los hombres, aunque sigo pensando que sería mucho mejor que compartieran ese tiempo de trabajo con los hijos. Lo digo por experiencia propia, yo fui afortunado al tener a mi madre todo el tiempo y no tener que permanecer la mayoría de mi tiempo en el colegio o con una empleada del servicio que poco o nada puede aportar en nuestras vidas" (Entrevistado 6).

De igual forma, se encuentra que hay una idea de que algunas mujeres perciben el matrimonio como una pérdida de la realización de sus metas individuales:

"De pronto llega un momento en que la otra persona, en el caso mío, siente como que se está perdiendo su vida, porque pensaba que la vida era menos rutinaria en convivencia” (Entrevistado 1).

"Ella manifestó que ya no sentía el amor de días anteriores, y además pensaba que sus sueños y su realización personal estaban en otra ciudad, por eso ella viajó a Bogotá” (Entrevistado 6).

Complementando lo dicho, algunos fragmentos de las entrevistas evidencian discursos en donde coexisten características tanto tradicionales como innovadoras sobre cómo debe ser una mujer. Por un lado, se destacan las funciones tradicionales de la mujer, el cuidado de los hijos y del esposo, pero destacando que deben repartirse las funciones del hogar entre hombre y mujer, y afirmando la importancia del amor de pareja y de una buena comunicación. 


\begin{abstract}
"Pues una mujer debe brindarle cariño al esposo y colaborarle en todo, con los hijos, sí me parece que esas son sus funciones, estar pendiente y brindarle cariño a uno. Como para tener una buena relación, pues que si se casan y van a vivir sin cariño y sin amor, eso no vale, ¿sí? Que uno también debe ser muy cariñoso con ella, colaborarle en las cosas que haiga que hacer en el hogar, pues dialogar, el dialogo es más que todo lo más importante en un hogar ¿sí? Si no hay diálogo, uno va como a las patadas, y entonces no funciona” (Entrevistado 7).
\end{abstract}

Por otro lado, se habla de la importancia de la educación de la mujer para alcanzar su independencia económica; y del hombre, para el sostenimiento económico del hogar:

\begin{abstract}
"Las mujeres de hoy en día también deben ser preparadas, mire, yo hablaba hace unos días con una niña [...] y yo le decía: mira, tú tienes que formarte y educarte muy bien, que te prepares antes de tener novio, que tú en el futuro no tengas que depender económicamente de un hombre para que puedas ser alguien. ¿Sí? Y lo contrario, si es un hombre tiene que formarse bien para que pueda llevar las riendas de un hogar. Porque eso es de juntos lados, o sea, no es de un solo lado, ¿sí me entiendes? No es tanto cómo debe ser el hombre o cómo debe ser la mujer, yo pienso que el problema es educativo y de formación personal" (Entrevistado 4).
\end{abstract}

\title{
Perspectivas en torno a la Política (formas de gobierno, leyes, políticas públicas y movimientos sociales) y la Igualdad
}

La política se tratará en relación a las perspectivas de los participantes sobre las formas de gobierno, las leyes, las políticas públicas y aquellos aspectos del ordenamiento jurídico donde los entrevistados ven reflejados los cambios entre hombres y mujeres antes expuestos.

Se destaca que algunos participantes encuentran similitudes entre las formas de gobierno y las formas familiares (maneras de distribuir poderes y de hacer relaciones en la familia), por tanto, los cambios y relaciones de poder dentro de la familia se relacionan y remiten a los cambios en las formas de gobierno, como una especie de reproducción micro social o a pequeña escala de las formas de relación y distribución a nivel político dadas a nivel macro social. La monarquía se relaciona con la tradicional familia patriarcal, donde el poder está en manos de un único monarca que ejerce su autoridad de forma vitalicia, lo cual nos remite a la definición ya dada de familia patriarcal, donde el poder está en manos del padre y se hereda al hijo varón en caso de muerte. De esto dan cuenta las entrevistas: 
"Los padres de esa época eran padres sentados a la cabeza del comedor, a la hora que era, y los demás tenían que cumplir, con una rigidez como venía de las costumbres de las monarquías, eso era aprendido de los señores latifundistas, o sea, el importante es el que manda, los demás obedecen, son subordinados, eso se veía en las familias, esos eran los padres en sí, pero eso era un aprendizaje, ¿no?, la madre decía: no vuelva a hacer eso o lo llevo a la corte de su papá, para que los juzgue, grave. Eso era copiado de la estructura social donde el que manda está arriba y los demás abajo” (Entrevistado 1).

Así, como se indicaba con anterioridad, el cambio en la forma de gobierno también se refleja en el cambio en la forma familiar; esto se evidencia con la democracia como forma de gobierno con respecto a una familia actual más dada a la distribución de roles y a la toma compartida de decisiones, basada en principios de igualdad y libertad:

"Hoy es democrática, igual que se dice del 'sistema democrático', hoy en las constituciones dice que todos somos iguales, entonces en los hogares, mal que bien, se sabe que todos son iguales, entonces hoy el muchacho dice 'me voy' y realmente se puede ir, incluso no lo buscan, no lo obligan, si puede comer chao y se va, porque se parece a la sociedad. Los hijos que quedan más cerca y duran más tiempo en su hogar, es porque el hogar es más democrático; unos dicen que un hogar consentidor o mal educador o qué se yo, genera problemas, pero es más democrático, antes no. 'Bueno, usted ya tiene esa niñita, ya la embarazó, entonces se va', o sea, la persona se iba regañada. Hoy puede que no, hoy puede que le diga 'no, pues si quieres te colaboro, que vengas, comparte con nosotros.' Eso es casi un reflejo de la sociedad” (Entrevistado 1).

Otro aspecto a considerar en su relación con la política y ley, es el de la custodia de los hijos, tema que dará paso a la propuesta de los participantes en relación con la implementación de políticas públicas a favor de la custodia compartida. Frente a la custodia de los hijos, hay una serie de insatisfacciones de los padres separados participantes que no tienen la custodia de los suyos, frente a las decisiones tomadas por la justicia, a las que en muchas ocasiones consideran injustas y/o desequilibradas:

"En los casos de separaciones y al hablar de custodia de niños hay muchas falencias adicionales que son, por ejemplo, la corrupción de los jueces que en cualquier sentido lleva muchas veces a decisiones que no son las mejores, sino las que por alguna conveniencia un juez o un fiscal o un operador de justicia cualquiera puede tomar una decisión que no está dirigida al bienestar de los niños. Yo creo que es eso" (Entrevistado 3).

En lo expresado se observa una perspectiva en la que primero se considera que la ley da prioridad a las mujeres, y que en cierta forma esta no es la decisión más adecuada y justa. Segundo, que no se consulta a los hijos para que tomen parte de esa decisión. Otros fragmentos así lo contemplan: 
"No pude disfrutar a mi hija, ella se ha impuesto ante la ley, ella hace lo que quiere, yo no puedo disfrutar de la niña, y la niña me adora a mí, me quiere muchísimo, pero a la niña no le han dado el espacio siquiera para que ella pueda decidir con quién se queda. Porque yo estoy seguro de que si a la niña le preguntaran de una forma neutra, la niña decide quedarse conmigo, porque ha sido mi adoración, es mis ojos, mejor dicho. Pero ante esas circunstancias, por lo que ella dijo, a mí me tocó ponerle una demanda por calumnia e injuria. Y será tan brava la palanca que ellos tienen, le voy a contar a usted, que hace cuatro años más o menos, o tres años, se puso la demanda y hasta este momento no creo que haya habido la primera situación por esa demanda. O sea, es como si hubiese acudido a la ley, pero una ley que no existe...” (Entrevistado 4).

"Yo pienso que por derecho, por ley, por ley humana, inclusive sin hablar de las leyes normales, por la ley humana, yo tendría derecho a disfrutar a mi hija y mi hija a disfrutar de su papá. (...) La ley continúa defendiendo mucho a la mujer, está desequilibrada, aunque también reconozco que hay hombres que son unas porquerías con las mujeres, porque también los hay, ¿no? Pero la ley está como tuerta de un ojito” (Entrevistado 4).

Sin embargo, la inconformidad manifestada por algunos padres separados sin custodia de sus hijos, no sólo es frente a la aplicación de la ley por parte de los jueces, también es frente a otras instituciones involucradas en el proceso de custodia o en procesos legales con la ex pareja. Por un lado se habla de la vulneración de derechos frente a procesos legales con la policía:

\footnotetext{
"Yo le decía, oiga, Lila, si usted sigue así va a llegar la policía, y yo que termino de decir policía y timbraron, la policía. Ella se bajó desde el tercer piso, abrió a los agentes y les dijo que el que estaba haciendo escándalo era yo, que yo venía borracho; entonces lo que hizo el agente de policía fue subir, olerme y me llevaron, duré 72 horas en un sitio que, sin mentirte, podría escribir un libro completo sobre eso: le vulneran a todas las personas los derechos humanos, un hueco terrible con la policía nacional, el caso es que yo salí a los tres días vuelto nada, de ahí, sin nada, sin desayuno, sin almuerzo, sin comida. Tres días, prácticamente, en un sitio de tortura” (Entrevistado 4).
}

Y por otro lado, frente al Instituto Colombiano de Bienestar Familiar², y en relación con el ejercicio de la ley:

“También pienso del Instituto Colombiano de Bienestar Familiar, que le falta mucho todavía por andar, y no pueden seguir institucionalizados, como tales, sino que deberían mirar otras cosas; porque uno no puede amarrar por bienestar familiar a un padre o a una madre, $\mathrm{o}$

2. El Instituto Colombiano de Bienestar Familiar, creado en 1968, es una entidad del Estado colombiano que trabaja por la prevención y protección integral de la primera infancia, la niñez, la adolescencia y el bienestar de las familias en Colombia. 
separarlo simplemente, y repartir los hijos como si fueran mercancías; tampoco se puede obligar a un padre a perder sus hijos, porque un decreto lo dice o porque una ley errada lo dice. Yo pienso que los que se divorcian son los padres, pero los padres no se divorcian en ningún momento de sus hijos, y la ley no debe amparar ese tipo de hechos” (Entrevistado 5).

Finalmente, en relación con la inconformidad ante el ejercicio de las leyes, se valora la implementación de leyes y políticas públicas diferentes como posibilidad de hacer justicia. En este sentido aparece la Fundación Papás por Siempre, entidad a la que pertenecen algunos de los participantes de la investigación, como posibilidad de influenciar en la política y, a partir de ahí, hacer cambios sociales y familiares:
"Cuando uno descubre que hay una entidad como Padres por siempre, Colombia, a mí me latía el corazón de la alegría, te cuento, me dio alegría, dije; 'esta es la oportunidad para recuperar a mi hija y yo sé que me van a escuchar', eso es lo primero que piensa uno, 'se va a hacer justicia,, ¿sí?” (Entrevistado 8).
"Es muy doloroso, pero quisiera que en un futuro no le pase a otros padres lo mismo. Yo pienso que nosotros somos un mecanismo para enderezar la justicia, así nos toque disfrazarnos de James Bond, Súperman, Batman o Robin, como cualquiera de nosotros, los miembros de Padres por Siempre Colombia; y yo pienso que sí se deben enderezar las leyes y las instituciones [...] Por eso estoy de acuerdo en la lucha de Padres por siempre Colombia, ¿no?, tú sí sabes cuál es: la custodia compartida” (Entrevistado 4).

Por otra parte, la implementación de políticas públicas también se refiere al uso de la ley para garantizar la equidad entre hombres y mujeres, en respuesta al cambio social actual y a la necesidad de justicia para hombres y mujeres. Esta idea se menciona cuando se habla de la separación y las nuevas configuraciones familiares vistas como una situación más convencional, y que se conciben como un resultado del cambio de roles e identidades de género, en especial de las mujeres, lo cual exige políticas acordes con estos cambios familiares y personales. A continuación se observa en lo expresado en un fragmento de entrevista:

"La separación rompe el tema de la familia como estaba configurado, se transforma, porque se van a otras familias [...] y hay que aprender a convivir con esas situaciones, tanto mamá, papá e hijos. Pero hay una nueva masculinidad con unos roles diferentes, igualmente pasa con la mujer, la sociedad tiene que empezar a generar políticas para que eso sea así, en los mismos colegios ya se ve, que el papá vive a un lado, que la mamá en otro y así... pero estamos un poco quedados en eso, sobre todo en Colombia y en estos países subdesarrollados" (Entrevistado 3). 
Finalmente, cabe decir que con respecto a lo dicho por los entrevistados, las políticas públicas y las leyes sobre separación conyugal y custodia de los hijos son aspectos importantes en la familia, pues se perciben como apoyo para nuevas relaciones sociales y, por consiguiente, familiares. Esto permite comprender la influencia e implicaciones del ejercicio adecuado de la ley en la vida social y personal del individuo. La política, más que una institución abstracta se identifica como una entidad que determina jerarquías y ejercicio del poder; y que está íntimamente ligada a la cotidianidad, a las decisiones y experiencias del individuo.

Es así que la percepción de algunos de los participantes, particularmente los miembros de la Fundación Padres por siempre, es la de ser tratados de manera desigual al momento de ejercer su derecho a ser padres. Esto se contrasta con la información encontrada en la página de la Fundación, en donde las lecturas y noticias dirigidas a los miembros de la entidad y a la comunidad en general, hacen uso de conceptos como "Feminismo igualitario"3, "Síndrome de Alienación Parental" (SAP) 4 y del calificativo "femi-nazi", con los cuales abanderan la lucha por la custodia compartida y el reconocimiento de las nuevas masculinidades, tema que se ampliará en la discusión que sigue.

\section{Discusión}

Después de la presentación de los hallazgos anteriores, se puede evidenciar cómo algunos participantes refieren conceptos que, como se veía en la introducción, han sido objeto de las luchas feministas. El concepto "Igualdad": "Hoy las constituciones dicen que todos somos iguales, entonces en los hogares, mal que bien, se sabe que todos son iguales" (Entrevistado 2). El concepto "Machismo": “-¿Y en qué crees que los hombres han cambiado? -Pues no ha sido mucho, creo que siguen siendo machistas. No es por nada, pero aún a las mujeres les cuesta mucho trabajo conseguir un buen empleo y no tienen las mismas oportunidades" (Entrevistado 2). La referencia a la "corresponsabilidad": "El hombre tiende a estar más en casa, a ayudar con las labores, a cambiar pañales, a ser más afectivo con los niños. El hombre deja de ser proveedor, solamente, sino que es tanto proveedor como responsable y generador de afecto hacia sus hijos, o sea, ya se habla de una nueva masculinidad, en la sociedad, es el nuevo hombre y la nueva mujer" (Entrevistado 3). Y la referencia a los "derechos humanos": "Yo podría escribir un libro

3. Feminismo igualitario es definido en la página web de la Fundación Padres por Siempre como opuesto al feminismo diferencialista, que considera que existe superioridad de las mujeres sobre los hombres.

4. Síndrome que tendría lugar cuando un progenitor manipula a su hijo mediante diferentes estrategias para obstaculizar o impedir que tenga relación con el otro progenitor. Este síndrome no es reconocido por el Manual Diagnóstico y Estadístico de los Trastornos mentales (DSM V) y aún presenta posturas contrapuestas sobre su existencia. 
completo sobre eso, le vulneran a todas las personas los derechos humanos" (Entrevistado 4); "Pienso que ha sido buena y lo merecen ya que tienen los mismos derechos que los hombres" (Entrevistado 6). Sin embargo, la referencia a estos conceptos es muy diversa y refleja que existen discursos contrapuestos que apoyan la igualdad de derechos entre hombres y mujeres, y otros que se apegan a los valores tradicionales en los que el rol de las mujeres se daba en el mundo privado.

Este hallazgo concuerda con las afirmaciones de De Keijzer, quien utiliza el concepto de "neomachismo" para mostrar cambios en las actitudes masculinas, determinando que "hay hombres instalados en el machismo light que ya no ejercen (o pueden ejercer) el patriarcado como lo hicieron sus padres y abuelos: ya negocian más las decisiones y permiten que trabaje la mujer fuera de casa (aunque prefieren que ella ya (sic) no gane más que ellos), pero mantienen un marco de referencia con un claro encuadre machista" (2001: 80). De Keijzer considera que hay una variable del neomachismo: "es el hombre machista-leninista, con un discurso igualitario de avanzada combinado con una práctica de género muy rezagada" (2001: 80).

Sin embargo, el análisis citado destaca también que hay padres que pretenden ser igualitarios y lo logran, desarrollando su capacidad de empatía y logrando un acercamiento afectivo con sus hijos. Por tanto, aunque hay padres que muestran compatibilidad entre sus discursos y prácticas de igualdad, se destaca por un lado la importancia social de reconocerse igual al otro, y por otro lado la imposibilidad de manifestar abiertamente acuerdo frente a modelos patriarcales de relación hombre-mujer.

Además, resulta evidente entre los participantes que las mujeres han cambiado a raíz de la "liberación femenina"; la palabra "feminismo" no se menciona en las entrevistas, sin embargo las expresiones "feminismo igualitario" o "feminismo diferencialista" aparecen dentro de la Fundación Padres por Siempre, a la que pertenecen algunos de los participantes, como una expresión de inconformidad al sentir que debido al feminismo las leyes favorecen a las mujeres cuando tienen el rol de madres, y que se reflejan en los discursos de algunos participantes con afirmaciones como: "Hay mujeres que están enseñadas a eso que llaman liberación" (Entrevistado 7); "La ley continúa defendiendo mucho a la mujer, está desequilibrada, aunque también reconozco que hay unos hombres que son unas porquerías con las mujeres, porque también los hay, ¿no? Pero la ley está como tuerta de un ojito" (Entrevistado 4). Este tema resulta interesante teniendo en cuenta lo afirmado por Bonino (2004) sobre las resistencias de los varones frente al cambio de las mujeres, pues encuentra que hay varones en contra del cambio de las mujeres, varones a favor del cambio, y varones ambivalentes. Este autor también reflexiona sobre los movimientos de varones, afirmando que:

Discuten la masculinidad como algo a transformar o conservar... tratando de dar respuesta a preguntas tales como: ¿Cómo es el varón de hoy? ¿Qué derechos le corresponden a los 
varones hoy?, y buscan dar respuesta grupal, de manera indirecta o directa, al desafío que suponen los cambios y avances de las mujeres y el feminismo. (Bonino, 2004: 3).

Esta reflexión sobre los movimientos de varones, resulta interesante teniendo en cuenta que algunos de los participantes son miembros de una Fundación que actúa como un colectivo a favor de las "nuevas masculinidades", y en la que algunos encuentran respuesta para defender su derecho a la custodia compartida de sus hijos. Sin embargo, la Fundación refleja solo una versión de estos movimientos, pues al igual que las perspectivas de los participantes, se caracterizan por la diversidad de posiciones. Un ejemplo se puede ver en la presencia de activistas y académicos que consideran al feminismo como su lucha:

El feminismo no sólo es una corriente de pensamiento que se alimenta del trabajo y del activismo de las mujeres: históricamente ha sido acompañado y alimentado del pensamiento, del activismo y del trabajo de hombres que lo consideran un elemento necesario para construir sociedades más justas y equitativas. (Bolio y Pinilla, 2015: 1).

Resulta interesante incluir aquí la postura de Fabbri (2015), que se pregunta cuál sería entonces el sujeto político de los colectivos de varones, pues considera que ubicar al varón como sujeto podría conllevar a la reproducción del binarismo de género, al sostenimiento de la división masculinidad/feminidad, y a la asociación entre masculinidad y varón, u hombre:

De esta forma se reproduce la identificación entre sexo y género, constituyéndose la masculinidad en atributo exclusivo y naturalizado de los "varones", e invisibilizando la existencia de otros sujetos que construyen sus formas de ser y estar en el mundo desde una noción de masculinidad, sin haber sido asignados como "varones" al nacer" y quizás también, sin nunca llegar a autodefinirse como tales. (Fabbri, 2015: 2).

Este autor da luces con respecto a lo que serían las tensiones entre los colectivos de masculinidades y los feminismos, explicando que mientras el enfoque feminista se ancla en el carácter relacional del poder, el enfoque masculinista se autocentra en las vivencias de la hombría, es decir, en los procesos identitarios masculinos, nutriéndose en los mismos estudios sobre masculinidades y generando distancia de las reflexiones feministas.

Basado en su experiencia, Fabbri considera que dentro de los colectivos de varones se usan expresiones colectivas como "profeministas", "antisexistas", "antimachistas", "antipatriarcales" e incluso "igualitarios", que aluden de manera directa o indirecta al enfoque feminista. Es difícil que estos colectivos se autodenominen feministas, debido a la necesidad de generar discursos propios de los varones, o a la imposibilidad de 
apropiarse del feminismo desde la socialización de género de los varones, o a que suele considerarse un espacio reclamado por y para mujeres feministas, un "terreno propio de las mujeres".

Ahora bien, si se va más allá de la dicotomía varón-mujer y se piensa el discurso feminista como defensa de lo femenino, mas no necesariamente propio de las mujeres, sino como conjunto de características, valores, roles e identidades atribuibles a cada ser humano, quizás podrían trascenderse las tensiones entre feminismos y nuevas masculinidades, y como se mencionaba previamente, luchar por el objetivo común: la igualdad. Este tema ha sido bien comprendido a nivel terapéutico:

Para despertar la verdadera masculinidad y ser libre, el hombre tiene que dejar de asociar la identidad masculina con la competitividad y con el poder, liberarse de las exigencias y mandatos que paralizan su capacidad de sentir y de exteriorizar sus emociones; es decir, integrar los valores femeninos. (Van Laere, 2010: 116).

Esta integración de aspectos femeninos se aprecia claramente cuando los participantes en el estudio mencionan los cambios de los hombres en relación con, por ejemplo, la incorporación de la afectividad en la relación con sus hijos; sin embargo, resulta complicado, como ya lo mencionaba Fabbris, que los varones se reconozcan como feministas, o que se reconozcan poseedores de valores o actividades femeninas. Esto habla de una lucha común a la que enfrentan los feminismos y los colectivos de hombres: la re-significación social de lo femenino y de lo masculino sin ubicar al uno por debajo del otro. Esta lucha es estructural y sin duda afectará tanto a hombres como mujeres a nivel social, político, económico y cultural.

Finalmente, de lo aquí discutido parece deducirse que los participantes, y los hombres en general, según lo enunciado por los autores mencionados, sea a través de un colectivo o desde sus experiencias personales toman posiciones diversas a favor o en contra del feminismo, es decir, se reorganizan en función de los cambios de las mujeres y de sus luchas, lo cual reafirma Thomas:

Este nuevo devenir femenino que, por supuesto, no puede dejar por fuera la pregunta por lo masculino. A medida que surge una nueva mujer, una nueva ciudadana, ella trastoca obligatoriamente los viejos pilares, los viejos parámetros de una masculinidad tradicional. A nueva mujer, nuevo hombre. Lo uno no puede ir sin lo otro. (2009: 109).

Se visibiliza la necesidad de investigaciones en torno a las identidades masculina y femenina que usen el género como principal categoría de análisis. Lo confirma Connell: "Se abre entonces una línea de investigaciones que busca entender la construcción de las identidades de género más allá de la dicotomía hombre dominador / mujer subordinada" (1997: 159). 


\section{Conclusiones}

Tomar discursos de hombres separados con hijos resultó provechoso, pues permitió vislumbrar elementos claves sobre el sujeto del feminismo: primero, que los participantes evidencian un cambio social-colectivo producto de la liberación femenina, que ha traído cambios individuales y familiares a mujeres y hombres; segundo, algunos de los participantes parecen percibir la lucha feminista como una lucha ajena que les quita el derecho al ejercicio libre de su paternidad; y tercero, que los discursos de los participantes son plurales, no hay posturas, percepciones ni experiencias idénticas en relación con sus vivencias como hombres, padres y separados. De tal forma, las experiencias y percepciones de los participantes reflejan necesidades que se explican desde la categoría género, que se han analizado por los investigadores de las nuevas masculinidades y que exponen elementos que podrían ser susceptibles de ser incorporados en la agenda de los feminismos.

Estos hallazgos aportan claves para entender el fenómeno de los colectivos de hombres y nuevas masculinidades (a los que se han incorporado algunos participantes, y que desde lo académico han estudiado las experiencias de los hombres para la comprensión de las masculinidades) que surgen en respuesta a los feminismos, revelando encuentros en la lucha a favor de la igualdad, el anti sexismo, el anti patriarcado y la reivindicación de la diferencia, y también desencuentros, al identificar los movimientos de hombres como auto centrados y con tendencias dicotómicas, y a los movimientos feministas como relacionales y apoyados en la perspectiva de género.

Ahora bien, frente a la pregunta sobre si podemos seguir hablando de "la mujer" como sujeto del discurso feminista, se puede decir que en principio sí, pero existen ciertas condiciones, según lo sugerido por Fabbri, Bonino, Bolio y Pinilla, Thomas y otros autores ya mencionados, y considerando las percepciones de los participantes sobre los cambios de los hombres en respuesta a los cambios de las mujeres. Hablar de las mujeres desde los feminismos es hablar desde lo relacional, histórico, cultural, etc., y en particular desde la igualdad. Aunque el punto de partida sea la lucha por los derechos de la mujer, el punto de llegada es una sociedad igualitaria, una sociedad de hombres y mujeres reconocidos como seres humanos en pleno ejercicio de su libertad y de sus derechos. Hablar de "las mujeres" es hablar de la igualdad y de los condicionamientos sociales a causa de género; las luchas feministas tienen implicaciones para todo el conjunto social y no exclusivamente para las mujeres.

En cuanto a la pregunta: ¿Cuáles serían las ventajas y desventajas para la práctica feminista?, se puede decir que hablar de "la mujer" como sujeto del feminismo, puede significar una vindicación histórica de la importancia de las mujeres en la historia humana, que puede ser tenida en cuenta para generar condiciones de igualdad. Sin embargo, la igualdad representa hablar de hombres y mujeres, por lo que tener en cuenta sólo a 
la mujer como sujeto del feminismo podría suponerse como una lucha desigual, pues ignoraría la carga impuesta que también la masculinidad y el ser hombre ha conllevado como producto del patriarcado. Por otro lado, es de tener en cuenta que una lucha por la igualdad de condiciones para todos los seres humanos, podría hacer olvidar a las mujeres y sus condiciones particulares indeseables bajo las cuales han estado expuestas.

La respuesta a estas preguntas resulta compleja, sin embargo, se concluye que los feminismos tienen en común la lucha por la emancipación de la mujer y más concretamente por la igualdad de condiciones, derechos y oportunidades. Hablar tanto de mujer como de igualdad implica una lucha en pro del ser humano y contra las barreras impuestas por la construcción genérica. La pluralidad del feminismo permite una lucha desde la teoría y la práctica que incluye a humanas y humanos y reivindica la igualdad y la libertad como sus valores esenciales; por tanto permite la re-significación de lo femenino en pro de su apropiación en la personalidad humana y por tanto en la constitución de seres humanos más realizados y completos.

El género, más que una categoría, es una perspectiva amplia que abarca categorías, hipótesis, interpretaciones y conocimientos relativos al conjunto de fenómenos históricos construidos en torno al sexo. El género está presente en el mundo, en las sociedades, en los sujetos sociales, en sus relaciones, en la política y en la cultura y es la principal herramienta de los feminismos para el alcance sus objetivos.

\section{Referencias}

ALONSO, J. (2005). “Marcela Lagarde: Una feminista contra el feminismo”. En: Revista Envio, Universidad Centroamericana UCA. (278).

BELTRÁN, E., MAQUIEIRA, V., ÁLVAREZ, S. Y SÁNCHEZ, C. (eds.) (2001). Feminismos. Debates teóricos contemporáneos. España, Madrid: Alianza Editorial.

BOLIO MÁRQUEZ, M. Y PINILLA MUÑOZ, D. (2015). El feminismo desde mi experiencia de vida construyendo puentes desde masculinidades diversas. Ponencia presentada en el V Coloquio Internacional de Estudios de Varones y Masculinidades. 14-16 enero 2015, Santiago de Chile.

BONINO, L. (2004). Obstáculos y resistencias masculinas al comportamiento igualitario.

Una mirada provisoria a lo intra e intersubjetivo. Recuperado: http://www.lazoblanco.org wpcontent/uploads/2013/o8manual/bibliog/material_masculinidades_0520.pdf

CONNELL, R. (1997). “La organización social de la masculinidad”. En: Valdés, T. y Olavarría, J. (eds.) Masculinidad/es. Poder y crisis. Chile: Ediciones de las Mujeres, no 24 . Isis Internacio nal-Flacso Chile. 
DE KEIJZER, B. (2001). Hasta donde el cuerpo aguante: Género, Cuerpo y Salud Masculina. Perú: Universidad Peruana Cayetano Heredia del Perú. Fondo Editorial.

FABBRI, L. (2015). ¿Qué (no) hacer con la masculinidad? Reflexiones activistas sobre los límites de los colectivos de varones/grupos de hombres. Ponencia presentada en el V Coloquio de Estudios de Varones y Masculinidades. 14-16 enero 2015, Santiago de Chile.

FIRESTONE, S. (1970). The dialectic of sex: The Case for Feminist Revolution. Nueva York: Bantam Books

FRIEDAN, B. (1964). The Feminine Mystique. New York: Norton.

FUNDACIÓN PADRES POR SIEMPRE. (2015). ¿Quiénes somos? Disponible en: http://www. padresporsiempre.com/quienes_somos.html

GODOY, F. (2010). Glosario de términos sobre género, sexualidad y discriminación.

Amnistía Internacional Sección Chilena. Disponible en: http://www.amnistiapr.org/ educacion/presentaciones/glosarioterminos.pdf

LAGARDE, M. (1996). Género y feminismo. Desarrollo humanoy democracia. Madrid: Horas y Horas la editorial.

MILLET, K. (1970). Sexual Politics. Nueva York: Avon Books.

MIYARES, A. (1999). "Feminismo y no “mujerismo”. En: Revista Meridiam. Recuperado de: http:// aliciamiyares.com/?p=172

THOMAS, F. (2009). “A nueva mujer, nuevo hombre”. Universidad de Antioquia. Memorias Cátedra Pública, pp.108-116

VALCÁRCEL, A. (2008). Feminismo en el mundo global. Ediciones Cátedra. Universitat de Valencia. Instituto de la mujer, Madrid.

VAN LAERE (2010). El resurgir de lo femenino. Claves para sanar la represión de lo femenino, inhibidora de la felicidad humana. Madrid: Gaia Ediciones. 